\title{
Reducing the Concentration to 0.4\% Enantiomeric Excess Hyperbaric Levobupivacaine (S75: R25) Provides Unilateral Spinal Anesthesia. Study with Different Volumes
}

\author{
Luiz Eduardo Imbelloni, TSA 1,2, Marildo A. Gouveia, TSA 2, Antonio Fernando Carneiro, TSA ${ }^{3}$, Renata Grigorio ${ }^{4}$
}

\begin{abstract}
Summary: Imbelloni LE, Gouveia MA, Carneiro AF, Grigorio R - Reducing the Concentration to 4\% Enantiomeric Excess Hyperbaric Levobupivacaine (S75: R25) Provides Unilateral Spinal Anesthesia. Study with Different Volumes.
\end{abstract}

Background and objectives: Unilateral spinal anesthesia may be obtained with hypobaric or hyperbaric solution. The objective of this study was to compare different doses of enantiomeric excess hyperbaric levobupivacaine to achieve unilateral spinal anesthesia.

Method: One hundred and twenty patients were randomized to receive $4 \mathrm{mg}, 6 \mathrm{mg}$ or $8 \mathrm{mg}$ of $0.4 \%$ enantiomeric excess levobupivacaine. The solutions were administered at the L3-L4, with the patient in a lateral position and kept at this position according to dose administration for 5 , 10 or 15 minutes. Sensory block (pinprick) and motor block (scale 0-3) were compared between the operated and contralateral sides.

Results: The onset of analgesia was rapid and comparable between groups. Sensory block was significantly higher in the operated than in nonoperated limb at all times of evaluation. Increasing the dose by $1 \mathrm{~mL}(2 \mathrm{mg})$ corresponded to an increase of two segments in the mode for the operated side. In the operated side, motor block $(\mathrm{MB}=3)$ of patients occurred in $31(77.5 \%)$ with $4 \mathrm{mg}, 38(95 \%)$ with $6 \mathrm{mg}$, and $40(100 \%)$ with $8 \mathrm{mg}$. There was a positive correlation between increased dose, blockade duration, and hypotension. All patients were satisfied with the technique used.

Conclusions: Spinal anesthesia with different volumes of enantiomeric excess hyperbaric bupivacaine (S75: R25) provided a 78\% incidence of unilateral spinal block, with the smallest dose used $(4 \mathrm{mg})$ the most efficient.

Keywords: Anesthesia, Spinal; Orthopedics; Anesthetics; Bupivacaine/analogs \& derivatives.

\section{INTRODUCTION}

The difference in density between the cerebrospinal fluid (CSF) and local anesthetics is a factor that should be considered to restrict the distribution of solutions within the subarachnoid space. Theoretically, unilateral spinal block could be obtained with hypobaric ${ }^{1}$ or hyperbaric ${ }^{2}$ solution injected into

Received from Instituto de Anestesia Regional, Complexo Hospitalar Mangabeira Gov. Tarcisio Burity, João Pessoa, PB, Brazil.

1. Professor of Anesthesiology, Faculdade de Medicina Nova Esperança (FAMENE), João Pessoa PB, Brazil.

2. Director, Instituto de Anestesia Regional, Complexo Hospitalar Mangabeira Gov. Tarcisio Burity, João Pessoa, PB, Brazil.

3. PhD in Medicine, Santa Casa de São Paulo; Head of the Department of Surgery, Universidade Federal de Goiás; Director of Professional Advocacy at SBA; Specialist in Intensive Care.

4. MSc, Health and Decision Models, Universidade Federal da Paraíba (UFPB), João

Pessoa; Complexo Hospitalar Mangabeira Gov. Tarcisio Burity, João Pessoa.

Submitted on February 22, 2012.

Approved on April 12, 2012.

Correspondence to:

Luiz Eduardo Imbelloni, MD

Rua Francisco Diomedes Cantalice, 21/802

Cabo Branco

58045210 - João Pessoa, PB, Brazil.

E-mail:dr.imbelloni@terra.com.br the subarachnoid space, with the patient in lateral position, so that the anesthetic forms a layer above (hypobaric) or below (hyperbaric) the midline.

In orthopedic outpatients undergoing lower limb surgeries involving only one member, unilateral spinal anesthesia has advantages over conventional anesthesia, such as fewer hypotension ${ }^{3}$, faster recovery from block ${ }^{1}$, and increased patient satisfaction ${ }^{4}$. There are several reasons to control the maximum level of sensory block. Lower limb surgeries require low levels of sensory block, resulting in higher cardiocirculatory stability ${ }^{4}$. With small doses of local anesthetics, side effects such as prolonged motor blockade, hemodynamic instability, and urinary retention may be avoided ${ }^{5,6}$. Lateral decubitus position, low doses of local anesthetic, needle orientation, and slow injection of anesthetic have been suggested as facilitators for unilateral spinal anesthesia ${ }^{7,8}$.

Levobupivacaine in proportions of $75 \%$ levorotatory and dextrorotatory $25 \%$ was obtained in $1997^{9}$. It was marketed in isobaric solution and used in adults ${ }^{10}$ and children ${ }^{11} . \operatorname{In} 2009$, $50 \%$ enantiomeric excess bupivacaine was used in $0.4 \%$ hyperbaric solution in different volumes with excellent results in infraumbilical procedures ${ }^{12}$. The aim of this prospective randomized study was to evaluate the incidence of unilateral block using different doses of $0.4 \%$ hyperbaric enantiomeric excess bupivacaine (S75: R25) with 5\% glucose, administered to patients undergoing orthopedic surgery in only one limb in the lateral decubitus position. 


\section{METHOD}

The Ethics Research Committee approved the study protocol and all patients were informed and agreed to participate in the study. Exclusion criteria were hypovolemia, pre-existing neurological disease, coagulation disorders, thromboprophylaxis for less than eight hours, infection at the puncture site, agitation and delirium, and the presence of indwelling catheters.

The incidence of unilateral blockade in several studies ranges from $65 \%$ to $90 \%$. Assuming a significance level of $5 \%$ and a power of $80 \%$, we obtained the required number of 81 patients. We selected 120 patients to ensure against data loss.

A solution of $50 \%$ enantiomeric excess levobupivacaine at $0.4 \%$ with $5 \%$ glucose was prepared from $0.5 \%$ isobaric enantiomeric excess levobupivacaine (S75: R25) (specific gravity at $37^{\circ} \mathrm{C}$ of $1.0058 \mathrm{~g} \cdot \mathrm{mL}^{-1}$ ) plus $1 \mathrm{~mL}$ of glucose $25 \%{ }^{12}$. Selected patients were ASA physical status I-II, without preanesthetic medication, aged between 20 and 60 years, scheduled for unilateral orthopedic surgery under spinal anesthesia. In all patients, pneumatic tourniquet was applied to the thigh and inflated to the maximum pressure of $350 \mathrm{~mm} \mathrm{Hg}$. Patients were randomly selected using coded envelopes prepared for the study and divided into three groups of 40 patients. Patients in Group 1 received $4 \mathrm{mg}(1 \mathrm{~mL})$, Group 2 received $6 \mathrm{mg}(1.5 \mathrm{~mL})$, and Group 3 received $8 \mathrm{mg}(2 \mathrm{~mL})$ of enantiomeric excess levobupivacaine $(\mathrm{S} 75, \mathrm{R} 25)$ at $0.4 \%$ with gravity of $1.0107 \mathrm{~g} \cdot \mathrm{mL}^{-1}$. Surgeries were knee videoarthroscopies, correction of ankle fractures with or without ligament injury, and implant removal below the knee.

After sedation with intravenous fentanyl $\left(1 \mu \mathrm{g} \cdot \mathrm{kg}^{-1}\right)$ and midazolam (1 mg), skin cleansing with chlorhexidine, and excess removal, spinal puncture was performed with the patient in lateral decubitus position with the involved limb down, through the median interspace L3-L4 after skin infiltration with lidocaine 1\%, using a 27G Quincke needle (B. Braun Melsungen) without introducer. After observing CSF confirming the correct position of the needle, 4,6 or $8 \mathrm{mg}$ of $0.4 \%$ enantiomeric excess hyperbaric levobupivacaine (S75: R25) were administered at a rate of $1 \mathrm{~mL} \cdot 30 \mathrm{~s}^{-1}$. Patients remained in the lateral position according to dose used: $4 \mathrm{mg}$ (5 minutes), $6 \mathrm{mg}$ (10 minutes), and $8 \mathrm{mg}$ (15 minutes) before being placed in a supine position for evaluation of the parameters studied and beginning of surgery.

Assessment of sensory and motor block was performed by another professional who was blinded to the patient's group allocation. The level of sensory block, defined as the lack of pinprick sensation, was assessed bilaterally at the midclavicular line, while motor block was assessed by modified Bromage scale ${ }^{13}$ : $0=$ free movement of lower limbs (LL), $1=$ inability to raise the limbs extended, 2 = inability to flex knees, $3=$ inability to move the ankles. Sensory and motor block were assessed in both limbs according to studied groups at 5, 10, and 15 minutes after surgery and comparison of involved and noninvolved limb was performed, as well as between groups. In case of blockade failure, another spinal anesthesia would be performed with $10 \mathrm{mg}$ of $0.5 \%$ hyperbaric bupivacaine. In case of insufficient time for the procedure, general anesthesia would be performed with a laryngeal mask. Hypotension (decreased SBP $>30 \%$ ward pressure) was treated with intravenous etilefrine $(2 \mathrm{mg}$ ) and bradycardia (heart rate $<45 \mathrm{bpm}$ ) was treated with intravenous atropine $(0.50 \mathrm{mg})$.

Duration of analgesia was determined by the time for sensation return to dermatome corresponding to the puncture site. Hemodynamic parameters were evaluated with 5 minutes interval throughout the procedure. Information regarding the blockade recovery time, surgical time, need for bladder catheterization, pain and treatment administered were recorded by an investigator. The time to begin ambulation was guided by the surgeon, and postoperative analgesia consisted of plexus blockade with peripheral nerve stimulator of lumbar or sacral nerve with $50 \mathrm{~mL}$ of $50 \%$ enantiomeric excess levobupivacaine at $0.2 \%$, according to site of operation, and ketoprofen (100 mg) and dipyrone (3 g) administered intravenously. Blockade and the first analgesic dose were performed at end of surgery in the operating room. It was not part of the study to evaluate the quality of postoperative analgesia.

Upon leaving the operating room, patients were asked to record their opinion about the technique. The alternatives were optimal, satisfactory or poor. Patients were followed-up for three days postoperatively in order to gather information about headache, transient neurologic symptoms (TNS) or back pain. Headache was classified as post-dural puncture if presented with worsening at sitting position, occipital or frontal location, increased with coughing, straining or sneezing. Back pain was considered TNS if the patient experienced pain and/ or dysesthesia in the back, buttocks, and legs after recovery with resolution within 72 hours.

The three treatment means were compared by analysis of variance. Probabilities of patient's level of satisfaction were compared by chi-square test and when it could not be used, Fisher's exact test was used. The Median Test was used to compare the medians of the three groups. The level of significance was $\alpha=0.05$.

\section{RESULTS}

Regarding patients' demographic data, height showed a significant difference among the three groups (Table I). Blockades were sufficient for the procedures performed and there was no need for additional general anesthesia.

The onset of analgesia was rapid and comparable between groups. The dose used did not influence the onset of sensory block, defined as latency time (Table II). There was difference between groups receiving $4 \mathrm{mg}$ and $8 \mathrm{mg}$ regarding duration of surgery ( $p$-value $=0.031$ ) and between groups regarding duration of blockade in different groups, showing increasing duration with increased dosage (4 mg $<6 \mathrm{mg}<8 \mathrm{mg}$ ) (Table II). Development of hypotension showed significant correlation with increased dosage ( $p$-value $=0.122$, Fisher's exact test) (Table II).

The spread of analgesia in the operated limb was different between the three groups in the first evaluation (Figure 1). The sensory level evaluated by the median test was lower in 
Table I - Patient Data

\begin{tabular}{lllll}
\hline & $4 \mathrm{mg}$ & $6 \mathrm{mg}$ & $8 \mathrm{mg}$ & $\mathrm{p}$ \\
\hline Age (years) & $40.57(13.57)$ & $41.22(9.72)$ & $38.65(11.31)$ & $0.591^{*}$ \\
Weight (kg) & $62.82(15.04)$ & $68.80(8.99)$ & $67.50(13.45)$ & $0.093^{*}$ \\
Height (cm) & $164.12(6.69)$ & $168.17(6.19)$ & $165.50(8.40)$ & $0.040^{*}$ \\
Sex (M/F) & $19 / 21$ & $23 / 17$ & $21 / 19$ & $0.530^{* *}$ \\
\hline
\end{tabular}

Mean (SD); M: male; F: female; Height: difference between groups $4 \mathrm{mg}$ and $6 \mathrm{mg}(\mathrm{p}=0.038) .\left(^{*}\right) 1$-Factor ANOVA, $\left(^{* \star}\right) X^{2}$ test.

Table II - Assessed Parameters

\begin{tabular}{|c|c|c|c|c|}
\hline & $4 \mathrm{mg}$ & $6 \mathrm{mg}$ & $8 \mathrm{mg}$ & p-value \\
\hline Latency (min) & $1: 46(0: 22)$ & $1: 41(0: 17)$ & $1: 39(0: 14)$ & $0.196^{*}$ \\
\hline $\begin{array}{l}\text { Surgery duration } \\
\text { (min) }\end{array}$ & $54(8)$ & $58(8)$ & $59(8)$ & $0.036^{*}$ \\
\hline $\begin{array}{l}\text { Block duration } \\
\text { (min) }\end{array}$ & $75(8)$ & $117(9)$ & $174(14)$ & $<0.001^{\star}$ \\
\hline Hypotension & 0 & 2 & 4 & $0.122^{\star \star}$ \\
\hline
\end{tabular}

(*) 1-Factor ANOVA; $\left.{ }^{* *}\right)$ Fisher's Exact Test.

the $4 \mathrm{mg}$ group, which was lower than $6 \mathrm{mg}$ group, which was lower than $8 \mathrm{mg}$ group (Figure 1). The mode for $\mathrm{T}_{12}$ was $4 \mathrm{mg}$, $\mathrm{T}_{10} 6 \mathrm{mg}$, and $\mathrm{T}_{8} 8 \mathrm{mg}$. The $2 \mathrm{mg}$ increase in dosage corresponded to a significant increase of two segments in mode between the three doses (Figure 1).

The time spent in lateral decubitus position according to dose reflected a selective unilateral blockade in 38 patients receiving $4 \mathrm{mg}$ (95\%), 32 receiving $6 \mathrm{mg} \mathrm{(80 \% ),} \mathrm{and} 24$ receiving $8 \mathrm{mg}(65 \%)$. The increase in dosage corresponded to a significant decrease unilaterally ( $p$-value $=0.001$ ) (Table III). At the end of surgery, there was an increase in unilateral block with all doses, which was $100 \%$ with $4 \mathrm{mg}, 85 \%$ with $6 \mathrm{mg}$, and $75 \%$ with $8 \mathrm{mg}$.

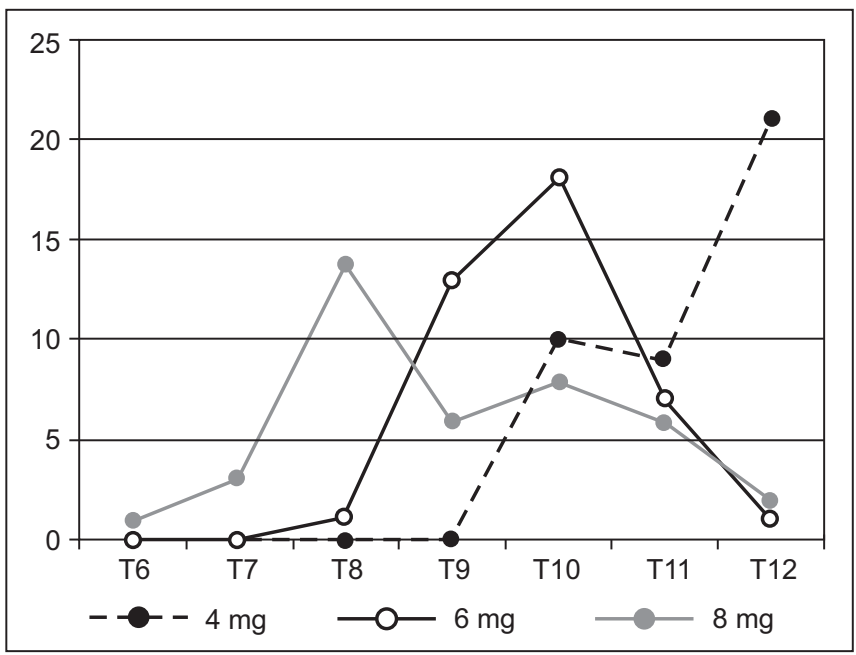

Figure 1 - Cephalad Spread on Operated Limb in the First Evaluation.

The mode was T12 with $4 \mathrm{mg}$, T10 with $6 \mathrm{mg}$, and T8 with $8 \mathrm{mg}$.
Table III - Incidence of Unilateral Blockade According to Dose Used in the First Evaluation and at the End of Surgery

\begin{tabular}{lllll}
\hline & $4 \mathrm{mg}$ & $6 \mathrm{mg}$ & $8 \mathrm{mg}$ & $\mathrm{p}$ \\
\hline $\mathbf{1}^{\text {st }}$ Evaluation & & & & $0.001^{*}$ \\
Yes (\%) & $38(95 \%)$ & $32(80 \%)$ & $24(65 \%)$ \\
$\quad$ No (\%) & $2(5 \%)$ & $8(20 \%)$ & $16(35 \%)$ & \\
End of Surgery & & & & $0.004^{*}$ \\
Yes (\%) & $40(100 \%)$ & $34(85 \%)$ & $30(75 \%)$ & \\
No (\%) & 0 & $6(15 \%)$ & $10(25 \%)$ & \\
\hline
\end{tabular}

$\left({ }^{*}\right)$ Fisher's Exact Test.

At the initial evaluation, complete motor block (grade 3 ) in operated limb occurred in 31 patients $(77.5 \%)$ receiving $4 \mathrm{mg}$, 38 patients receiving $6 \mathrm{mg}(95 \%)$, and 40 patients receiving $8 \mathrm{mg}(100 \%)$ (Figure 1). There is significant difference between doses ( $p$-value $<0.001$ ). At the end of the procedure, no patient showed grade 3 motor block with $4 \mathrm{mg}$, versus 32 patients with $6 \mathrm{mg}$ and 34 with $8 \mathrm{mg}$.

In the contralateral limb, absence of motor block (grade 0) at the beginning of surgery occurred in 38 patients with $4 \mathrm{mg}$ versus 32 with $6 \mathrm{mg}$ and none with $8 \mathrm{mg}$ (Figure 3), confirming that the lower dose results in a higher incidence of unilateral blockade. At the end of surgery, no motor block was present in all patients with $4 \mathrm{mg}$, in 34 patients with $6 \mathrm{mg}$, and in 26 patients with $8 \mathrm{mg}$.

Patients who developed hypotension (2 with $6 \mathrm{mg}$ and 4 with $8 \mathrm{mg}$ ) required only one dose of the vasopressor. There was no bradycardia in patients of all groups. All patients had an optimal satisfaction with the technique used. No patient had post-dural puncture headache or urinary retention. There were no complaints of back pain or pain in the buttocks or legs during the three subsequent days.

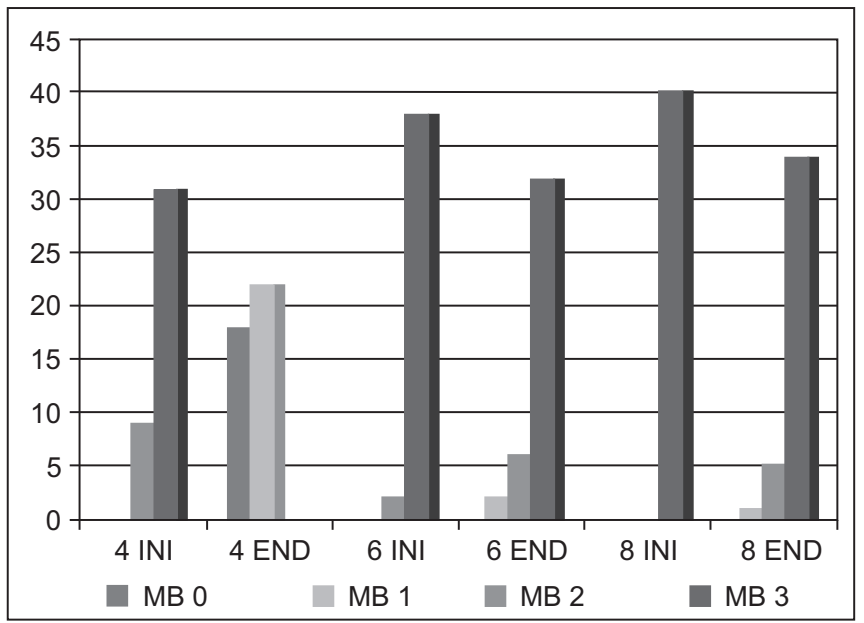

Figure 2 - Motor Block of Operated Limb in the First Evaluation and at the End of Surgery.

INI: Initial; END: Final. 


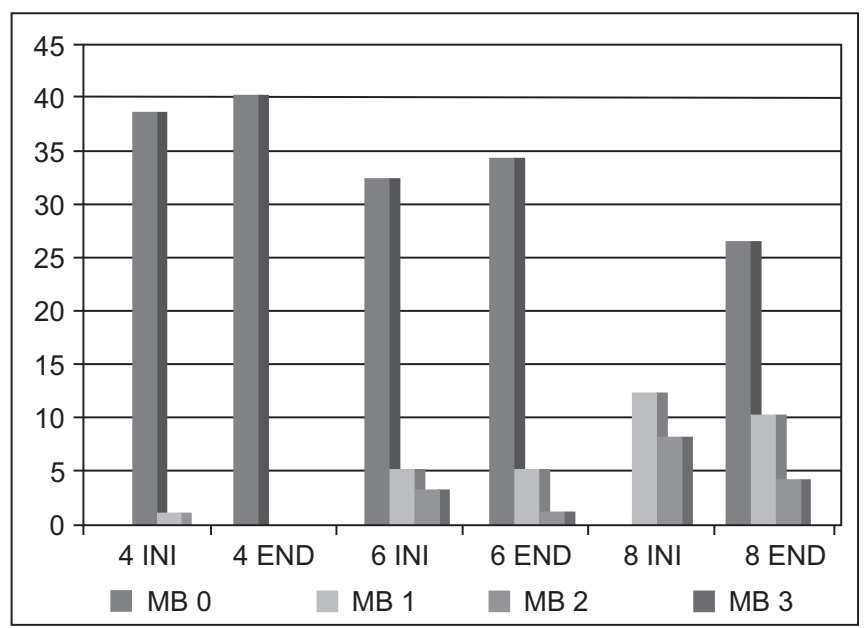

Figure 3 - Motor Block of Contralateral Limb in the First Evaluation and at the End of Surgery.

INI: Initial; END: Final.

\section{DISCUSSION}

In this study, appropriate levels of anesthesia were achieved for surgeries of a single lower limb, using $4 \mathrm{mg}, 6 \mathrm{mg}$, or $8 \mathrm{mg}$ of $50 \%$ enantiomeric excess levobupivacaine at $0.4 \%$ hyperbaric. The $4 \mathrm{mg}$ dose $(1 \mathrm{~mL})$ provided only unilateral blockade in $95 \%$ of patients, $6 \mathrm{mg}(1.5 \mathrm{~mL})$ in $80 \%$, and $8 \mathrm{mg}(2 \mathrm{~mL})$ in $65 \%$, showing that selectivity is dependent on the mass of injected anesthetic into the subarachnoid space. The rapid onset of action was no difference between doses, and duration of action was dose dependent.

Unilateral spinal anesthesia may result in sensory and motor hemiblock preferably on one side. The purpose of applying spinal anesthesia restricted to one of lower limbs is to minimize the extent of the blockade on the side to be operated, as well as obtaining surgical anesthesia throughout the procedure. This goal was achieved in $78.3 \%$ of patients in the first assessment and $86.6 \%$ of patients at the end of surgery.

The drugs evaluated for use in anesthesia depend on the national pharmacopoeia regulation and commercial factors. Enantiomeric excess levobupivacaine (S75: R25) at $0.5 \%$ was marketed only in isobaric formulation. In a previous study, a protocol was designed to evaluate the drug in hyperbaric solution at $0.4 \%$ in $5 \%$ glucose with different volumes, showing that it can easily replace the $0.5 \%$ solution ${ }^{12}$, a fact confirmed in this study.

Hyperbaric bupivacaine is prepared with the addition of glucose, and additions of glucose were tested at $5 \%$ and $10 \%$, with the $8 \%$ concentration presenting less variation in the extent of blockade. The use of bupivacaine $0.75 \%$ in $8 \%$ glucose showed no advantage over the $0.5 \%$ concentration ${ }^{14}$. Between 2 and $4 \mathrm{~mL}$, the increased volume produced no change in dispersion, but produced an increase in duration of action, which is related to dose increase ${ }^{14}$. In children, hyperbaric bupivacaine with $0.9 \%$ or $8 \%$ glucose produced similar spinal anesthesia regarding success, cephalad spread of block, re- covery, and side effects ${ }^{15}$, showing that there is no need for high doses of glucose to make the anesthetic hyperbaric. In a previous study with the same $0.4 \%$ solution with $5 \%$ glucose, and volumes ranging from 2.5 and $5 \mathrm{~mL}$, there was greater cephalad spread, as well as increased duration of action with increasing dose ${ }^{12}$. In this study, the same result was achieved with low doses for unilateral spinal anesthesia, showing that unilateral blockade was higher with the lower dose and inversely proportional to the dose used.

Obtaining a selective unilateral blockade depends on the anesthetic, dose, and time spent in the lateral decubitus position. High doses of bupivacaine $(12-20 \mathrm{mg})$ show significant blockade migration, even after 1 hour in the lateral decubitus position ${ }^{16}$, while small doses of bupivacaine $(5-8 \mathrm{mg})$ result in a restricted blockade after 10-15 minutes in the lateral decubitus position ${ }^{17}$. The best outcome for unilateral blockade occurred when low doses of hyperbaric or hypobaric bupicacaine were used and the patient remained in the lateral decubitus position for $10-20$ minutes $^{6}$. In this study, the patient was maintained in the lateral decubitus position with time depending on the dose used showing that the lowest dose $(4 \mathrm{mg})$ required less time than moderate $(6 \mathrm{mg})$ or high doses $(8 \mathrm{mg})$. This resulted in a higher selectivity with the lowest dose (95\%) compared with the higher dose (65\%).

By definition, baricity is the relationship between the density of injected solution and the density of CSF. Mean baricity of CSF is $1.00059 \pm 0.00020$ g.mL ${ }^{-1}{ }^{18}$. The baricity of local anesthetics may be increased by the addition of glucose. The baricity of $0.4 \%$ enantiomeric excess hyperbaric levobupivacaine (S75: R25) is $1.0107 \mathrm{~g} \cdot \mathrm{mL}^{-1}$ at $37^{\circ} \mathrm{C}$, thus hyperbaric in all patients. This fact was confirmed when 94 of 120 patients (78.3\%) had pure unilateral blockade (only in a single limb), when anesthetized in lateral decubitus position, and only 26 patients $(21.7 \%)$ had some degree of blockage in the nonoperated limb. Large variations in volume and concentration of local anesthetic have little role in its spread to the leptomeningeal channel ${ }^{19}$ while the total amount of molecules injected into the spinal canal has a more important role. In this study with dose ranging from 4 to $8 \mathrm{mg}$, the highest dose resulted in a greater spread of anesthesia and lower selectivity.

The duration of spinal anesthesia is not only dependent on the choice of anesthetic, but also on the dose. The use of 6,8 , and $10 \mathrm{mg}$ of $0.75 \%$ hyperbaric bupivacaine and the patient remaining in the lateral decubitus position resulted in a mean duration of analgesia of 93,123 , and 147 minutes, respectively ${ }^{20}$. The recovery time using $5 \mathrm{mg}$ of $5 \%$ hyperbaric bupivacaine was $2 \mathrm{~h} 30 \mathrm{~min}^{2}$, which was similar to $5 \mathrm{mg}$ of $0.15 \%$ hypobaric bupivacaine (2h32min) ${ }^{1}$ and $5 \mathrm{mg}$ of $0.5 \%$ isobaric bupivacaine (2h34min) ${ }^{21}$. The study of different doses of $0.4 \%$ enantiomeric excess levobupivacaine (S75: R25) for infraumbilical surgeries reflected in a dose-dependent duration of action ${ }^{12}$. In this study with the same solution and in the same concentration, low doses of 4,6 and $8 \mathrm{mg}$ provided recovery times of 75,117 , and 174 minutes, respectively, with positive correlation between doses.

The use of hyperbaric anesthetic at low doses $(5 \mathrm{mg})^{2}$ yielded only two unilateral block (without contralateral motor or sympathetic blockade), resulting in great cardiocirculatory sta- 
bility without hypotension and bradycardia. In the present study at doses ranging from 4 to $8 \mathrm{mg}$ of $0.4 \%$ hyperbaric enantiomeric excess levobupivacaine (S75, R25), excellent cardiocirculatory stability was seen with the onset of hypotension in two patients with 6 , four with $8 \mathrm{mg}$ and none with $4 \mathrm{mg}$.

The use of $0.4 \%$ enantiomeric excess hyperbaric levobupivacaine in different doses proved to be safe to avoid the onset of TNS ${ }^{12}$. In the present study, there was no case of TNS at doses of 4-8 $\mathrm{mg}$ in the same concentration. Another factor that may have contributed to the non-emergence of TNS in our study was the lack of complete blockade of the lower limbs.

Similar to other study ${ }^{15}$, the addition of $5 \%$ glucose to enantiomeric excess levobupivacaine (S75, R25) showed that there is no need for a high concentration of glucose to make the anesthetic hyperbaric. There is much consistency in the finding that the usual concentration of $8 \%$ glucose for hyperbaric spinal anesthesia is exaggerated, thus allowing the addition of adjuvant analgesics (opioids or not) to the lower dose of local anesthetic and conservation of hyperbaricity. Thus, many other studies can be performed with hyperbaric spinal anesthesia in the context of multimodal analgesia. Likewise, the results obtained by reducing the concentration to $0.4 \%$ enantiomeric excess levobupivacaine (S75, R25) are similar to results from other studies obtained with hyperbaric bupivacaine.

In conclusion, $0.4 \%$ enantiomeric excess hyperbaric levobupivacaine (S75: R25) with 5\% glucose provided a rapid onset of sensory and motor block-level, block duration and patients' dose-dependent satisfaction. Permanence time is dose-dependant. The lower dose yielded the highest incidence of selectivity in both analgesia and motility. 


\section{REFERENCES}

1. Imbelloni LE, Beato L, Gouveia MA - Baixas doses de bupivacaína hipobárica para raquianestesia unilateral. Rev Bras Anestesiol, 2003;53:579-585.

2. Imbelloni LE, Beato L, Cordeiro JA - Raquianestesia unilateral com baixa dose de bupivacaína 0,5\% hiperbárica. Rev Bras Anestesiol, 2004;54:700-706.

3. Casati A, Fanelli G, Aldegheri G et al - Frequency of hypotension during conventional or asymetric hyperbaric spinal block. Reg Anesth Pain Med, 1999;24:214-219.

4. Imbelloni LE. O uso racional da raquianestesia. Em: Imbelloni LE, Tratado de Anestesia Raquidiana, Medidática Informática Ltda, Curitiba, 2001, Capítulo 8, p. 74.

5. Pittoni G, Toffoletto F, Calcarella G et al - Spinal anesthesia in outpatient knee surgery: 22-gauge versus 25-gauge Sprotte needle. Anesth Analg, 1995;81:73-79.

6. Kuusniemi KS, Pihlajamäki KK, Pitkänen MT - A low dose of plain or hyperbaric bupivacaine for unilateral spinal anesthesia. Reg Anesth Pain Med, 2000;25:605-610.

7. Tanasichuk MA, Schultz EA, Matthews JH et al - Spinal hemianalgesia: An evaluation of a method, its applicability, and influence of the incidence of hypotension. Anesthesiology, 1961;22:74-85.

8. Casati A, Fanelli G, Cappelleri G et al - Low dose hyperbaric bupivacaine for unilateral spinal anaesthesia. Can J Anaesth, 1998;45:850854.

9. Simonetti MPB, Valinetti EA, Ferreira FMC - Avaliação da atividade anestésica local da S(-)bupivacaína: Estudo experimental in vivo no nervo ciático de rato. Rev Bras Anestesiol, 1997; 47:425-434.

10. Imbelloni $L E$, Beato $L$ - Comparação entre bupivacaína racêmica (S50:R50) e mistura enantiomérica de bupivacaína (S75:R25), ambas isobáricas, a $0,5 \%$, em raquianestesia. Estudo em cirurgias ortopédicas. Rev Bras Anestesiol, 2001;51:369-376.

11. Imbelloni LE, Vieira EM, Beato L, Sperni F - Raquianestesia com a mistura enantiomérica de bupivacaína a $0,5 \%$ isobárica (S75-R25) em crianças com idades de 1 a 5 anos para cirurgia ambulatorial. Rev Bras Anestesiol, 2002;52:286-293.

12. Imbelloni LE, Cordeiro JA - Mistura em excesso enantiomérico de $50 \%$ de bupivacaína (S75:R25) hiperbárica para procedimentos cirúrgicos infraumbilicais. Estudo com diferentes volumes. Rev Bras Anestesiol, 2009;59:3-10.

13. Bromage $P R-A$ comparison of the hydrochloride and carbon dioxide salts of lidocaine and prilocaine in epidural analgesia. Acta Anaesthesiol Scand, 1965; Suppl XVI:55-69.

14. Chambers WA, Scott DB - Spinal anesthesia with hyperbaric bupivacaine: effect of added vasoconstrictors. Anesth Analg, 1982;61:4952.

15. Kokki $\mathrm{H}$, Hendolin $\mathrm{H}-$ No difference between bupivacaine in $0.9 \%$ and $8 \%$ glucose for spinal anaesthesia in small children. Acta Anaesthesiol Scand, 2000;44:548-551.

16. Povey HMR, Jacobsen J, Westergaard-Nielsen J - Subarachnoid analgesia with hyperbaric $0.5 \%$ bupivacaína: Effect of 60 -min period of sitting. Acta Anaesthesiol Scand, 1989;33:295-297.

17. Esmaoglu A, Boyaci A, Ersoy $O$ et al - Unilateral spinal anesthesia with hyperbaric bupivacaine. Acta Anaesthesiol Scand, 1998;42:10831087.

18. Lui ACP, Polis TZ, Cicutti NJ - Densities of cerebrospinal fluid and spinal anaesthetic solutions in surgical patients at body temperature. Can J Anesth, 1998;45:297-303.

19. Stienstra R, Green N - Factors affecting the subarachnoid spread of local anesthetic solution. Reg Anesth, 1991;16:1-166. 
IMBELLONI, GOUVEIA, CARNEIRO E COL.

20. Kim KC, Moneta MD - Unilateral spinal anesthesia can be obtained with low dose bupivacaine. Anesthesiology, 1992;77:(Suppl 3A):A803.

21. Imbelloni LE, Beato L, Gouveia MA - Low dose of isobaric $0.5 \%$ bupivacaine for unilateral spinal anesthesia. Rev Bras Anestesiol, 2004;54:423-430. 